\title{
Prevention of peptic ulcer by aqueous extract of Aegle marmelos leaf in rats
}

\author{
Sharmin Rahman, Mohammad Rezaul Quader, Md. Ismail Khan \\ Department of Pharmacology, Dhaka Medical College, Dhaka, Bangladesh
}

\begin{abstract}
Background and objectives: Aegle marmelos (Bael), a medicinal plant, has been widely used indigenously to treat many diseases in Bangladesh and other countries. The present study was carried out to evaluate the efficacy of $A$. marmelos leaf to prevent ethanol induced gastric ulcer in a rat model.

Methods: Thirty two Wister albino rats of either sex, weighing between $100-150 \mathrm{~g}$, were fed $200 \mathrm{mg} / \mathrm{kg}$ or $400 \mathrm{mg} / \mathrm{kg}$ aqueous extract of A. marmelos leaves one hour prior to oral administration of $90 \%$ ethanol ( $1 \mathrm{ml} / 200$ gm body weight) to induce gastric ulcer. The animals were sacrificed after one hour and ulcer scores and index were determined. The protective efficacy of $A$. marmelos aqueous extract was expressed as percentage protection of ulcer.

Results: Aqueous extract exhibited significant $(\mathrm{p}<0.05)$ dose dependent protection against gastric ulcer formation by ethanol in rat stomach. Percentage protection of ulcer with 200 $\mathrm{mg} / \mathrm{kg}$ and $400 \mathrm{mg} / \mathrm{kg}$ of aqueous extract of A. marmelos leave were $19.3 \%$ and $37.2 \%$ respectively compared to standard anti-peptic ulcer drug omeprazole $(50.4 \%)$.
\end{abstract}

Conclusion: Thus, crude extracts of $A$. marmelos leave have been shown to have potential ability to prevent experimentally induced peptic ulcer formation in animal model.

IMC J Med Sci 2018; 12(1): 11-14

\section{Introduction}

Peptic ulcer refers to ulceration in the lower esophagus, stomach, duodenum, and jejunum, and rarely in the ileum adjacent to a diverticulam. Herbal medicine is fast emerging as an alternative treatment to available synthetic drugs for the treatment of peptic ulcer possibly due to lower costs, easy availability, fewer adverse effects and perceived effectiveness. A. marmelos, commonly known as 'Bael' in Bengali language, is one such plant that grows wildly all over Bangladesh and also in many countries of South East Asia including India, Sri Lanka, Myanmar, Thailand and Indochina [1]. Extensive chemical investigations on various parts of the tree have been carried out. Many active constituents has been isolated from $A$. marmelos and reported to have anti-ulcer, anti- inflammatory and antimicrobial properties [1]. The present study was designed to demonstrate the protective effect of aqueous extract of $A$. marmelos leaves on ethanol induced gastric ulcer in rat model.

\section{Materials and Methods}

The study was conducted at the Department of Pharmacology, Dhaka Medical College, Bangladesh. Leaves of $A$. marmelos were collected from Botanical garden, Mirpur, Dhaka and authenticated by the Bangladesh National Herbarium.

Preparation of plant extract: Collected leaves ( $1 \mathrm{~kg}$ ) of A. marmelos were sun dried and the dried material was crushed to coarse powder with mechanical grinder. Aqueous extract was prepared

Address for Correspondence:

Dr. Sharmin Rahman, Assistant Professor, Department of Pharmacology, Ibrahim Medical College, 122 Kazi Nazrul Islam Avenue, Shahbagh, Dhaka-1000, Bangladesh. Email:sharminrahman241980@gmail.com 
at the Drug Research Laboratory, Center for Advanced Research of Science (CARS), Dhaka University. The dried powdered plant part was soaked in distilled water at room temperature for 72 hour and filtered. The filtrate was concentrated under vacuum rotator evaporator $\left(40-50^{\circ} \mathrm{C}\right)$ and semi-liquid extract of $A$. marmelos was obtained and preserved at $4^{0} \mathrm{C}$ until used. The extract was diluted with measured amount of distilled water prior to use to get the required concentration.

Animals: Thirty two Wister albino rats of either sex, weighing between 100-150g were kept under standard condition of light and temperature, fed with standard rat pellet diet and allowed to drink water ad libitum.

Experiment Design: Preventive anti-peptic ulcer activity of aqueous extracts of $A$. marmelos leaves was assessed in ethanol induced gastric ulcer in rat model $[2,3]$. Experimental animals were randomly selected irrespective of sex and divided into 4 groups, each group comprising of 8 rats. Rats in group-I served as control and the other three comprised study groups. All the animals were kept fasting for 24 hours prior to administration of drugs. Rats in group-I received distilled water 5 $\mathrm{ml} / \mathrm{kg}$ body weight and served as negative control. Rats in group-II and III received aqueous extract of A. marmelos leaves $200 \mathrm{mg} / \mathrm{kg}$ and $400 \mathrm{mg} / \mathrm{kg}$ body weight respectively in 1-2 ml distilled water by baby Ryle's tube. Rats in group-IV received omeprazole $20 \mathrm{mg} / \mathrm{kg}$ body weight orally as standard reference drug. One hour after administration of $A$. marmelos leave extract and omeprazole, gastric ulcer was induced in rats by administering $90 \%$ ethanol ( $1 \mathrm{ml} / 200$ gm body weight) orally. One hour after ethanol administration rats were sacrificed. Their stomachs were isolated, washed gently under clean water and cut open along the greater curvature. The stomachs were then fixed in $10 \%$ formalin and the ulcers were scored as: no ulcer-0, red coloration of mucosa-0.5, spot hemorrhage- 1 , hemorrhagic streaks-1.5, ulcer-2 and perforation-3.

Ulcer index (UI) was calculated using the following formula: $\mathrm{UI}=\mathrm{U}_{\mathrm{N}}+\mathrm{Us}_{\mathrm{s}}+\mathrm{UP}_{\mathrm{P}} \times 10^{-1}$, where $\mathrm{UN}_{\mathrm{N}}=$ average of number of ulcers/lesions per animal, Us $=$ average number of severity score of lesions and $\mathrm{UP}_{\mathrm{P}}=$ percentage of animal with ulcers incidence. Percentage protection of ulcer was calculated by the following formula:

Percentage protection $=$

(mean ulcer index of control-mean ulcer index of test) $\times 100$ mean ulcer index of control

\section{Statistical Analysis}

All the results have been expressed as the mean \pm standard error of mean (SEM). The significance of the differences between treatment and control group were calculated using student's t-test.

\section{Results}

The ulcer score, UI and protective effect of aqueous extract of $A$. marmelos leaves and omeprazole on ethanol induced gastric ulcer is shown in Table- 1 . The mean ulcer score and UI of rats fed with distilled water only (Group-I: control) were $2.83 \pm 0.21$ and $18.16 \pm 0.21$ respectively. Aqueous extract in doses of $200 \mathrm{mg} / \mathrm{kg}$ body weight (GroupII) and $400 \mathrm{mg} / \mathrm{kg}$ body weight (Group-III) produced a significant dose dependent decrease in ulcer score to $1.58 \pm 0.15$ and $0.83 \pm 0.25$ while ulcer index to $14.66 \pm 0.15$ and $11.40 \pm 0.25$ respectively. The

Table-1: Effects of aqueous extract of A. marmelos leaves on ethanol induced gastric ulcer in rats

\begin{tabular}{lcccc}
\hline Group & $\begin{array}{c}\text { Number } \\
\text { of rats }\end{array}$ & $\begin{array}{c}\text { Ulcer score } \\
(\text { mean } \pm \text { SEM })\end{array}$ & $\begin{array}{c}\text { Ulcer index } \\
(\text { mean } \pm \text { SEM })\end{array}$ & $\begin{array}{c}\% \text { Protection } \\
\text { of ulcer }\end{array}$ \\
\hline Group-I & 8 & $2.83 \pm 0.21$ & $18.16 \pm 0.21$ & - \\
Group-II & 8 & $1.58 \pm 0.15$ & $14.66 \pm 0.15^{*}$ & $19.27 \%$ \\
Group-III & 8 & $0.83 \pm 0.25$ & $11.40 \pm 0.25^{*}$ & $37.22 \%$ \\
Group-IV & 8 & $0.67 \pm 0.17$ & $9.0 \pm 0.17^{* *}$ & $50.44 \%$ \\
\hline
\end{tabular}

Note: Gr-I=Distilled Water, Gr-II=A marmelos extract $200 \mathrm{mg} / \mathrm{kg}, \mathrm{Gr}-I I I=A$ marmelos extract $400 \mathrm{mg} / \mathrm{kg}$, Gr-IV=Omeperazole $20 \mathrm{mg} / \mathrm{kg}$.; $p<0.05^{*}, p<0.001 * *$ compared to $\mathrm{Gr}-\mathrm{I}$. 

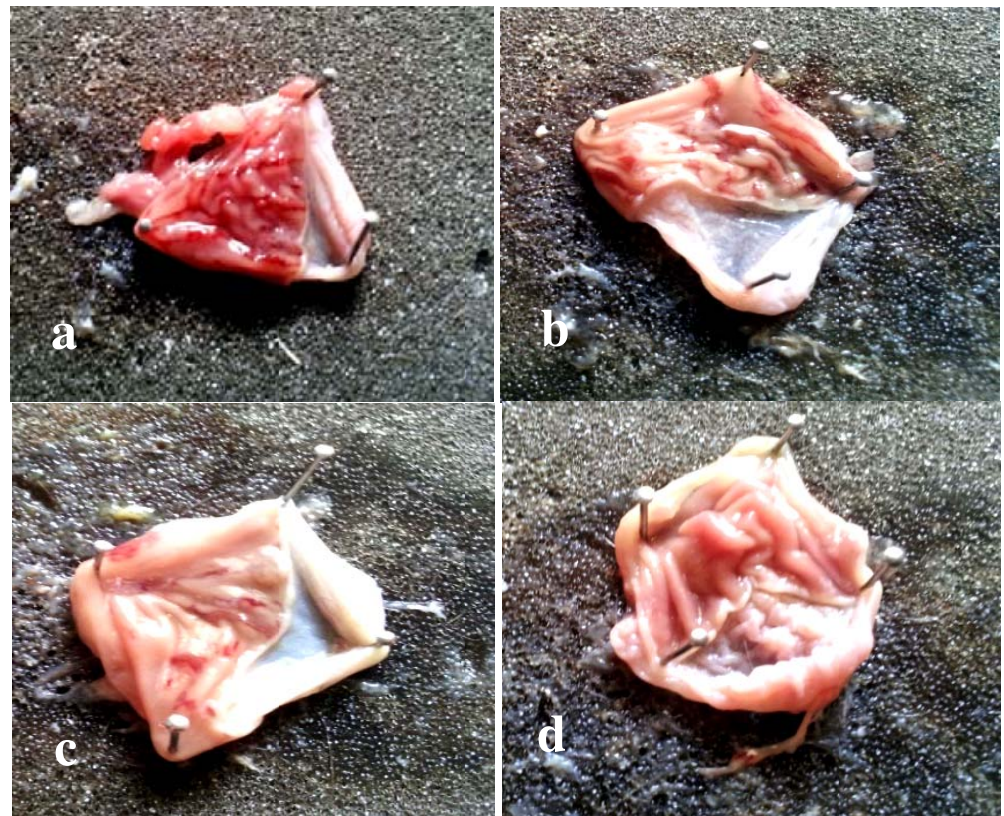

Fig.1: Photograph showing effect of aqueous extract of A. marmelos leaves on ethanol induced ulcer in rat stomach. 1a: ethanol treated gastric mucosa of rat, 1b and 1c: effect of $200 \mathrm{mg} / \mathrm{kg}$ and $400 \mathrm{mg} / \mathrm{kg}$ body weight dose of aqueous extract of A. marmelos leaves and $\mathbf{1 d}$ : effect of omeprazole $(20 \mathrm{mg} / \mathrm{kg})$.

differences compared to control Group-I were statistically significant $(\mathrm{p}<0.05)$. Omeprazole $(20$ $\mathrm{mg} / \mathrm{kg}$ body weight) also produced highly significant $(\mathrm{p}<0.001)$ decrease in ulcer score $(0.67 \pm 0.17)$ and ulcer index $(9.0 \pm 0.17)$ compared to control group $(2.83 \pm 0.21$ and 18.16 \pm 0.21$)$ respectively (Table-1). The percentage protection of ulcer was $19.27 \%, 37.22 \%$ and $50.4 \%$ with 200 $\mathrm{mg} / \mathrm{kg}, 400 \mathrm{mg} / \mathrm{kg}$ dose of aqueous extracts of $A$. marmelos leaves and omeprazole respectively.

\section{Discussion}

Many studies have demonstrated the importance of natural products in drug discovery. In this study, ability of aqueous extract of $A$. marmelos leaf to prevent ethanol induced gastric ulcer in rat model has been studied. The effect of aqueous extract of A. marmelos leaves was compared to standard antipeptic ulcer drug, omeprazole. The ulcer index parameter was used for evaluation of ulcer protective activity. Earlier studies have shown that aqueous extract of $A$. marmelos leaves have variable ulcer protective effects in animal models with ethanol induced gastric ulcer [4,5]. Aqueous extracts of $A$. marmelos leaves, $200 \mathrm{mg} / \mathrm{kg}$ and 400 $\mathrm{mg} / \mathrm{kg}$ body weight, produced significant $(\mathrm{p}<0.05)$ anti-ulcer effect, compared to control and omeprazole ( $20 \mathrm{mg} / \mathrm{kg}$ body weight). Percentage protection against ulcer with 200 and $400 \mathrm{mg} / \mathrm{kg}$ body weight of aqueous extract of $A$. marmelos leaves was $19.3 \%$ and $37.2 \%$ respectively.

The study showed that prior administration of aqueous extract of $A$. marmelos leaf can prevent peptic ulcer significantly. It exhibited a dose dependent protective effect. However, we did not examine the adverse effects of the leaf extract on hepatobiliary, renal and other systems of the animal. However, further study is required to determine the active compound responsible for anti-ulcer property. Studies regarding pharmacokinetics, pharmacodynamics, toxicology and posology of the extract or its active compound should be carried out to develop a useful ulcer protective agent for human therapy. 
Acknowledgment

Authors acknowledge the valuable opinion and advice of Prof. Nazma Haque during the preparation of manuscript.

\section{Author's contribution}

SR was responsible for experiments, literature search and manuscript writing, MRQ helped in sample collection, laboratory work and manuscript writing and MIK designed the study and was overall supervisor.

\section{Competing interest}

The authors declare that they have no competing interests.

\section{Funding source}

None

\section{References}

1. Sharma PC, Bhatiya V, Bansal N, Sharma A. A review on Bael tree. Nat Prod Rad. 2007; 6(2): 171-178.

2. Gupta J, Kumar D, Gupta A. Evaluation of gastric anti-ulcer activity of methanolic extract of Cayratia trifolia in experimental animals. Asian Pac J Trop Dis. 2012; 99-102.

3. Nwagba CA, Ezugwa CO, Eze CC, Anowi FC, Ezea SC, Nwakile CD. Anti ulcer activity of Bombax buonopozense p. beauv. aqueous leaf extract (Fam: Bombacaceae). J Appl Pharm Sci. 2013; 3(2): 139-142.

4. Madhu C, Hindu K, Sudepthi CD, Maneela P, Reddy KV, Bhagya SB. Anti ulcer activity of aqueous extract of $A$. marmelos leaves on rats. Asian J pharm Res. 2012; 2(4): 132-135.

5. Shenoy AM, Singh R, Samuel RM, Yedle R, Shabraya AR. Evaluation of anti ulcer activity of A. marmelos leaves extract. Int J Pharm Sci Res. 2012; 3(5): 1498-1501. 